\title{
Zn Doped Nanocrystalline CuCl Thin Films for Optoelctronic Applications
}

\author{
K. V. Rajani ${ }^{1}$, F. Olabanji Lucas ${ }^{2}$, M. M. Alam ${ }^{2}$, S. Daniels ${ }^{1}$ and P. J. McNally ${ }^{2}$ \\ ${ }^{1}$ Nanomaterials Processing Laboratory, NCPST, School of Electronic Engineering, Dublin City \\ University, Dublin 9, Ireland \\ ${ }^{2}$ Nanomaterials Processing Laboratory, RINCE, School of Electronic Engineering, Dublin City \\ University, Dublin 9, Ireland.
}

\begin{abstract}
We report on the use of $\mathrm{Zn}$ as an n-type dopant in $\mathrm{CuCl}$ thin films for optoelectronic applications, wherein maximum n-type doping of the order of $10^{18} \mathrm{~cm}^{-3}$ has been achieved. $\mathrm{Zn}$ doped nanocrystalline $\mathrm{CuCl}$ thin films are successfully deposited on glass and Si substrates by pulsed dc magnetron sputtering. Structural and morphological properties are investigated using X-ray diffraction (XRD) studies and Scanning Electron Microscopy (SEM), respectively. The conductivity of the $\mathrm{CuCl}: \mathrm{Zn}$ films is examined using the four point probe technique. An order of magnitude increase in the conductivity of $\mathrm{CuCl}$, by the doping with $\mathrm{Zn}$ is reported herein. The doped $\mathrm{CuCl}$ films display strong room temperature cathodoluminescence (CL) at $\lambda \sim 385 \mathrm{~nm}$, which is similar to that of the undoped films. Hall Effect measurements show an n-type conductivity of the doped films.
\end{abstract}

\section{INTRODUCTION}

The search for wide band gap semiconductor materials has great importance in the optoelectronics industry due to their interesting applications in the development of solid state emitters $[1,2]$. Zincblende $\gamma-\mathrm{CuCl}$ is a direct band gap $(\sim 3.39 \mathrm{eV}$ at room temperature) compound semiconductor with much larger excitonic binding energy ( $190 \mathrm{meV}$ ) [3] when compared to the III-N [4] and $\mathrm{ZnO}$ [5] semiconductors. This high binding energy of $\mathrm{CuCl}$ guarantees excitonic luminescence at room temperature and beyond. Further to this, it has a relatively small lattice mismatch with $\mathrm{Si}(<0.4 \%)$, which may improve the reliability of the light emitting devices made out of these based on $\mathrm{CuCl} / \mathrm{Si}$ structures. All of these advantages of $\mathrm{CuCl}$ can be used for the development of an exciton based semiconducting optical emitter by effectively doping the material system.

Numerous reports on the electrical characteristics of $\mathrm{CuCl}$ have been published so far. The total electrical conductivity and the electron hole conductivity in copper halides have been reported by Wagner et al. many years ago [6]. They reported p-type conductivity for the as deposited copper chloride films due to the presence of copper vacancies caused by the excess halogen. The p-type conductivity in $\mathrm{CuBr}$ has been demonstrated by Knauth et al. using Hall Effect experiments [7]. The first report of the n- type doping of the $\mathrm{CuCl}$ films was performed by the co-evaporation of $\mathrm{ZnCl}_{2}$ and $\mathrm{CuCl}$ by O'Reilly et al. [8]. They reported a relatively low carrier concentration of the order of $10^{16} / \mathrm{cm}^{3}$ for the doped $\mathrm{CuCl}$ films due to the simultaneous inclusion of $\mathrm{Zn}$ and $\mathrm{Cl}$ in the $\mathrm{CuCl}$ film. 
Here we present the first report on the pulsed dc magnetron sputtering deposition of the $\mathrm{CuCl}: \mathrm{Zn}$ films on glass and Si substrate using a $\mathrm{CuCl} / \mathrm{Zn}$ target. Unlike the co- evaporation of $\mathrm{CuCl}$ with $\mathrm{ZnCl}_{2}$, this method can avoid the problem of the inclusion of $\mathrm{Cl}$ along with the $\mathrm{Zn}$ in to the $\mathrm{CuCl}$ film, as was outlined in [8].

\section{EXPERIMENTAL}

$\mathrm{CuCl}: \mathrm{Zn}$ was deposited using pulsed dc magnetron sputtering of a $\mathrm{CuCl} / \mathrm{Zn}$ target, by varying the $\mathrm{wt} \% \mathrm{Zn}$ in the target from $0-5$, on ultrasonically cleaned glass and Si substrates. An ENI RPG-100 pulse generator was used to drive a planar magnetron fitted with the target. Sputtering was carried out in pure argon atmosphere at a pressure of $5.5 \times 10^{-3}$ mbar with a target to substrate distance of $6 \mathrm{~cm}$. The power density at the target and duty cycle of the pulse used were $1.73 \mathrm{~W} / \mathrm{cm}^{2}$ and $40 \%$, respectively. The substrate was kept at floating potential and the thickness of the samples was $350 \pm 20 \mathrm{~nm}$.

The sheet resistance and thickness of the film was measured using a four point probe measurement set-up (Veeco), and Nano-R Atomic Force Micrograph (AFM), and thereby resistivity can be calculated. X-Ray diffraction analysis was carried out using Copper $\mathrm{K} \alpha$ radiation of wavelength $1.54 \AA$ from a Bruker D8 advance instrument to determine the crystallinity of the $\mathrm{CuCl} / \mathrm{Zn}$ films. Morphology of the thin films was investigated using Scanning Electron Microscopy. UV/Vis absorption spectra of the films were explored using a Perkin Elmer Lambda $40 \mathrm{UV} / \mathrm{V}$ is spectrometer in a range of wavelength from $320-420 \mathrm{~nm}$. The room temperature cathodoluminescence studies were carried out using LEO Stereoscan 440 SEM coupled with a Gatan MonoCL instrument. Carrier concentration and Hall mobility were determined by the van der Pauw method.

\section{RESULTS AND DISCUSSION}

Figure 1 shows the $\mathrm{X}$-ray diffraction spectra of the $\mathrm{Zn}$ doped $\mathrm{CuCl}$ films deposited by sputtering of the $\mathrm{CuCl}$ target with wt \% of $\mathrm{Zn}$ varying from 0-5. All of the XRD spectra gave prominent peaks of $\mathrm{CuCl}$, with a strong orientation along the (111) plane (corresponding to a $2 \theta$ value of $28.5^{\circ}$ ). The XRD spectra also show peaks corresponding to (220) and (311) plane orientations, with $2 \theta$ values of $47.6^{\circ}$ and $56.3^{\circ}$ respectively. All the peak positions are in good agreement with the corresponding ICDD data for polycrystalline $\mathrm{CuCl}$. The XRD spectra indicate that the $\mathrm{Zn}$ doping doesn't degrade the structural properties of the $\mathrm{CuCl}$, but improves the crystallinity of the $\mathrm{CuCl}$, by texturing the orientation along the (111) direction. It can be observed from the XRD analysis that the intensity of the (111) peak has the highest value for the $3 \mathrm{wt} \% \mathrm{Zn}$ doped sample. The average crystalline sizes of the undoped as well as the doped $\mathrm{CuCl}$ films, calculated using Scherrer equation was found to vary between $\sim 37$ and $49 \mathrm{~nm}$.

The conductivities of the $\mathrm{CuCl}: \mathrm{Zn}$ films are investigated using the sheet resistance values of the films, deduced from the four point probe measurements. The conductivity of the undoped $\mathrm{CuCl}$ film is calculated as $\sim 4 \times 10^{-3} \mathrm{~S} \mathrm{~cm}^{-1}$ and that of the 1,3 and $5 \mathrm{wt} \% \mathrm{Zn}$ doped samples are $\sim 1 \times 10^{-2}, 2 \times 10^{-2}$ and $9 \times 10^{-2} \mathrm{Scm}^{-1}$ respectively. Thus far, the conductivity of the $\mathrm{CuCl}$ thin film can be increased by an order of magnitude by the doping with $\mathrm{Zn}$. 


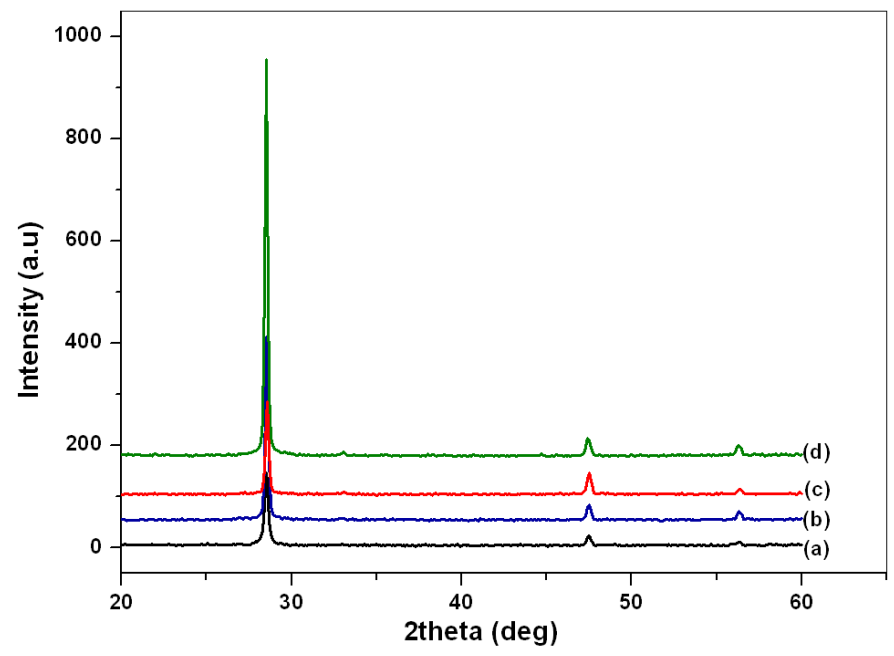

Figure 1. XRD $\theta-2 \theta$ spectra of the undoped (a) $\mathrm{CuCl}$ and (b) $1 \%$, (c) $5 \%$ and (d) $3 \%$ (wt \%) Zn doped samples.

Preliminary Hall effect measurements illustrate an $\mathrm{n}$ type conductivity of the $\mathrm{Zn}$ doped $\mathrm{CuCl}$ films, with an average carrier concentration of $\sim 1 \mathrm{x} 10^{18} \mathrm{~cm}^{-3}$ and a Hall mobility of $\sim 10^{-1}$ $\mathrm{cm}^{2} \mathrm{~V}^{-1} \mathrm{~s}^{-1}$ for the $3 \mathrm{wt} \% \mathrm{Zn}$ doped films, for example.

It is important to confirm that the n-doping process does not impact negatively on the unique excitonic behaviour of the deposited $\gamma-\mathrm{CuCl}$ films. Thus, Figure 2 shows the room temperature $\mathrm{UV}-\mathrm{V}$ is absorption spectra of the $\mathrm{CuCl}: \mathrm{Zn}$ films deposited on glass substrates, with a varying wt $\%$ of $\mathrm{Zn}$ in the target.

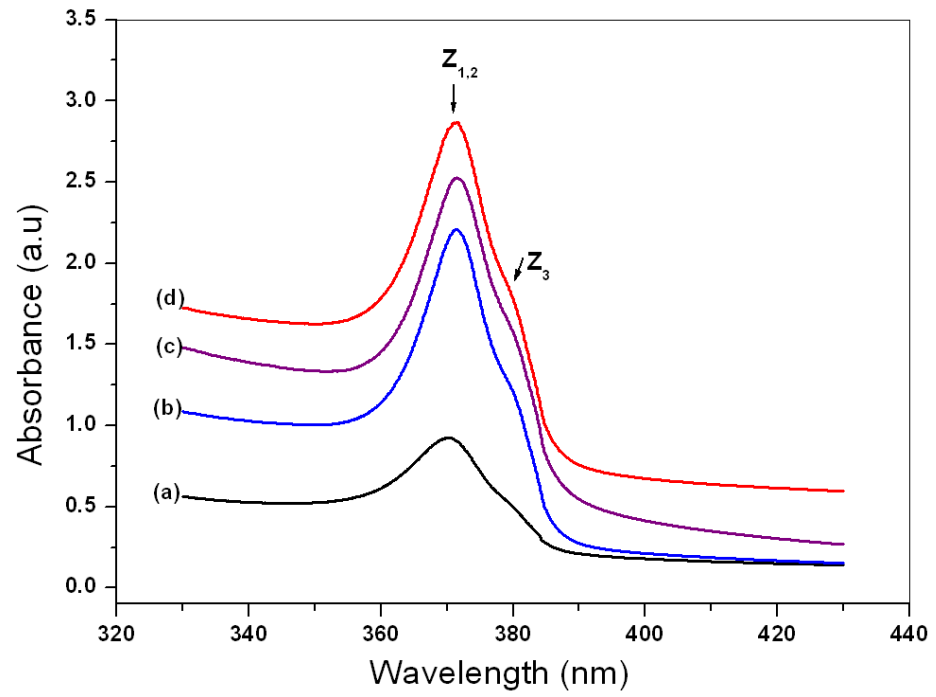

Figure 2. UV-Vis absorption spectra of the (a) $0 \%$, (b) $1 \%$, (c) $3 \%$ and (d) $5 \%$ (wt $\%$ ) Zn doped $\mathrm{CuCl}$ thin films. 
The absorption peaks are separated from each other for ease of observation. All undoped samples including the doped films confirm the presence of the low energy and the high energy excitonic bands, labelled $Z_{3}$ and $Z_{1,2}$, respectively. The peak positions of $Z_{3}$ and $Z_{1,2}$ are at $\sim 379 \mathrm{~nm}$ and $\sim 372 \mathrm{~nm}$ respectively, which are in good agreement with the previously reported data for the undoped $\mathrm{CuCl}[8]$.

Figure 3 shows the SEM image of a typical 3 wt \% $\mathrm{Zn}$ doped $\mathrm{CuCl}$ film. It illustrates the presence of the triangular grains in the films.

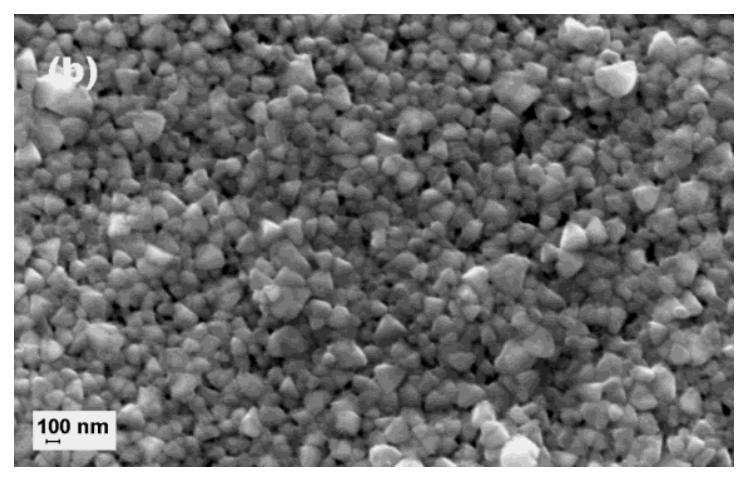

Figure 3. Scanning Electron Micrograph (SEM) image of a typical 3 wt \% $\mathrm{Zn}$ doped $\mathrm{CuCl}$ film.

The grain size obtained from the SEM picture is higher than that inferred using XRD analysis. All the remaining samples (undoped, 1 and $5 \% \mathrm{Zn}$ doped) also show the similar trend.

The observed grains in the SEM image can be considered as clusters of the nanocrystalites [9].

The room temperature CL measurements on all samples revealed identical excitonic features. A typical room temperature CL spectrum of the $3 \mathrm{wt} \% \mathrm{Zn}$ doped $\mathrm{CuCl}$ film is shown in figure 4. The strong emission at a wavelength of $\sim 384.7 \mathrm{~nm}(\sim 3.22 \mathrm{eV})$ corresponds

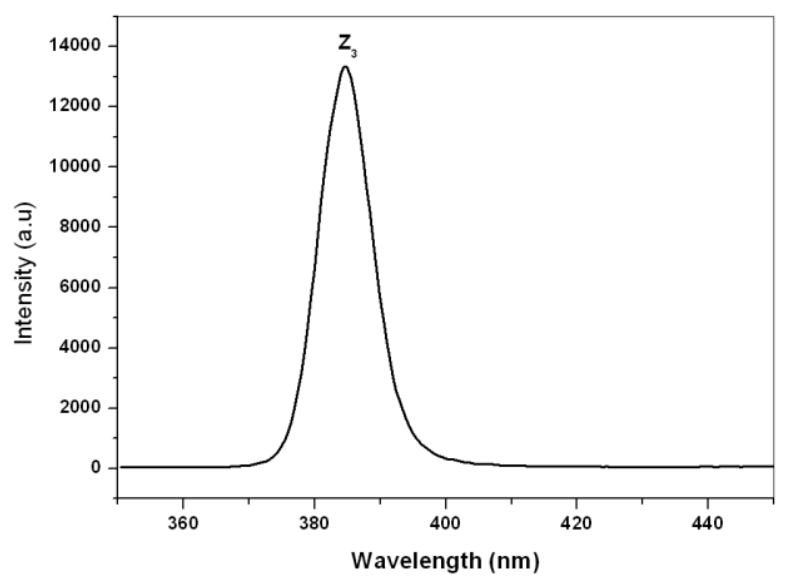

Figure 4. Room temperature cathodoluminescence spectrum of a typical 3 wt \% $\mathrm{Zn}$ doped $\mathrm{CuCl}$ film. 
to the well known $\mathrm{Z}_{3}$ free exciton peak of $\mathrm{CuCl}$, and this is in good agreement with the previous reports. The $Z_{3}$ free excitonic emission is due to the coupling of the lowest conduction-band state $\Gamma_{6}$ to the uppermost valance-band hole $\Gamma_{7}$. This indicates that the doping of $\mathrm{Zn}$ has no harmful effect on the luminescence properties of the $\mathrm{CuCl}$.

\section{CONCLUSIONS}

$\mathrm{Zn}$ dopant is used to achieve n-type doping of $\gamma$ - $\mathrm{CuCl}$ thin films, which are deposited by pulsed dc magnetron sputtering of $\mathrm{CuCl}$ targets containing a controlled wt $\%$ of $\mathrm{Zn}$. The conductivity of $\mathrm{CuCl}$ films can be controllably increased by an order of magnitude by the incorporation of $\mathrm{Zn}$ in the $\mathrm{CuCl}$ film. Hall effect measurements confirm the doping to be n-type, and XRD, UV-Vis absorption and CL measurements confirmed that the controlled incorporation of $\mathrm{Zn}$ in $\mathrm{CuCl}$ films does not significantly alter the structural, absorption and luminescence properties of $\mathrm{CuCl}$.

\section{ACKNOWLEDGMENTS}

This project was funded by the Enterprise Ireland Commercialisation Fund for Technology Development (Project\# CFTD/07/IT/331). This work was part-funded by the Irish Higher Education Authority PRTLI "INSPIRE" project. The authors would like to thank Mr. Billy Roarty for his technical support.

\section{REFERENCES}

1. S. Nakamura, T. Mukai and T. Senoh, Appl.Phys.Lett. 64, 687 (1994).

2. D. M. Bagnall, Y. F. Chen, Z. Zhu, T. Yao, S. Koyama, M. Y. Shen and T. Goto Appl.Phys.Lett. 70, 2230 (1997).

3. M. Nakayama, H. Ichida and H. Nishimura J.phys.: Condens.Matter 11, 7653 (1999).

4. B. Monemar, Phy.Rev.B 10, 676(1974).

5. Y. R. Ryu, T. S. Lee and H. W. White, Appl.Phys.Lett. 83, 87 (2003).

6. J. B. Wagner, C. Wagner, J.Chem.Phys. 26, 1597 (1957).

7. P. Knauth, Y. Massiani and P. Pasquinelli, Phys.Stat.Sol., 165, 461(1998).

8. L. O'Reilly, A. Mitra, G. Natarajan, O. F. Lucas, P. J. McNally, S. Daniels, D. C. Camron, A. L. Bradley and A. Reader, J.Cryst.Growth 287, 139(2006).

9. Gomathi Natarajan, S. Daniels, D. C. Cameron, L.O’Reilly, A. Mitra, P. J. McNally, O. F. Lucas, R. T. Rajendra Kumar, I. Reid and A. L. Bradley, J. Appl. Phys. 100, 033520 (2006). 